\title{
Impact of Turbulence Modeling on Numerical Accuracy and Efficiency of Compressible Flow Simulations
}

Thomas J. Coakley, Ames Research Center, Moffett Field, California

September 1986

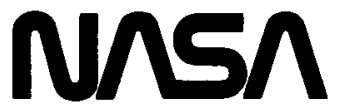

National Aeronautics and

Space Administration

Ames Research Center

Moffett Field, California 94035 


\title{
IMPACT OF TURBULENCE MODELING ON NUMERICAL ACCURACY AND EFFICIENCY OF COMPRESSIBLE FLOW SIMULATIONS
}

\author{
Thomas J . Coakley \\ NASA Ames Research Center \\ Moffett Field, CA 94035
}

The basic objective of this work is to compare and evaluate the performance of various turbulence models which are used in the numerical simulation of complex turbulent flows. The approach utilizes the Reynolds-averaged compressible NavierStokes equations in which the Reynolds stresses and heat fluxes are mathematically modeled by suitable turbulence models. This paper focuses on the simulation of transonic flows about a 2-D airfoil and the estimation of performance characteristics such as lift and drag. Attention is given to separated flows where differences between model predictions are generally greater than those observed for unseparated flows.

The turbulence models used in the present study are eddy viscosity models which include the family of zero-, one-, and two-equation models. Zero- and one-equation models are numerically the simplest of the eddy viscosity models but lack the generality of the two-equation models because their length scales must be determined algebraically rather than from a field equation. However, two-equation models are more complicated than zero- and one-equation models, and these complications can sometimes lead to numerical difficulties.

Six turbulence models are studied in this paper. They are the zero-equation models of Cebeci and Smith ${ }^{1}$, Baldwin and Lomax ${ }^{2}$, and Johnson and $\mathrm{King}^{3}$, and the two equation $k-\varepsilon$ and $q-\omega$ models respectively of Chien ${ }^{4}$ and the present author, Refs. 5 and 6. These models are listed in Table I. All of these models utilize the procedure of integration-to-the-wall in which no-slip boundary conditions are applied at solid surfaces. For the zero-equation models, a common formulation is used in the airfoil wake region which is due to Cebeci $^{7}$. The location of transition in the computations was taken from the experimental boundary-layer trip locations except in the cases of the two-equation $q^{-\omega}$ model predictions where the transition locations were allowed to occur naturally.

The numerical differencing method consists of a second-order implicit upwind differencing algorithm combined with a finite volume discretization technique which produce accurate resolution of shock waves and discontinuities ${ }^{8}$. Additional features of the method include the use of spatially varying time steps to speed convergence to a steady state and an implicit treatment of boundary conditions. Inviscid boundary conditions at far field boundaries are based on the method of characteristics and account for circulation due to lift.

Paper presented at 10th International Conference on Numerical Methods in Fluid Dynamics, Beijing, China, June 23-27, 1986. 
The airfoil investigated in the present study was the RAE 2822 airfoil which has extensive experimental documentation ${ }^{9}$. Three cases were investigated, Cases 1 , 9, and 10, which correspond respectively to unseparated subcritical flow, unseparated supercritical flow and separated supercritical flow. The experimental conditions of Mach number, Reynolds number and geometric angle of attack for each of the three cases are shown in Table I. Since the calculations were done in free air, the angle of attack must be changed from the experimental or geometric angle of attack to account for wind tunnel wall effects. The angles of attack used in the calculations are shown in Table $I$ and were obtained from the recommendations in Ref. 9 .

The numerical grid used in the computations is shown in Fig (1). It consists of an algebraically generated $240 \times 60 \mathrm{C}$-grid. The mesh spacing in the $\mathrm{y}$ direction at the surface was such that $\mathrm{y}^{+}$at the first mesh point was less than one everywhere on the airfoil. The spacing in $\mathrm{x}$ over the central portion of the airfoil was $\Delta \mathrm{X} / \mathrm{C}=.013$ with the spacings reduced at the leading and trailing edges. The far field boundary was placed approximately 20 chords from the airfoil surface.

Surface pressure and upper surface skin friction and displacement thickness distributions are compared for Case 1 in Fig. (2). It is apparent that the surface pressure distributions predicted by the turbulence models are in good agreement with one another and with experiment. Larger differences between model predictions and experiment are indicated by the skin friction and displacement thickness distributions. Models which are in best agreement with experiment on skin friction, especially near the trailing edge, are the C-S, B-L and $q-\omega 2$ models. The best models in predicting displacement thickness are the $J-K$ and $q-\omega 2$ models. The lift and drag predictions for this case are shown in table I. It appears that all three zero-equation models give better predictions of drag than the two-equation models while the $J-K$ and $q-\omega 2$ models give the best predictions of lift.

The second case studied was the unseparated supercritical case 9. Computed Mach contours for this case obtained using the $J-K$ model are shown in Fig. (3). Surface pressure and upper surface skin friction and displacement thickness distributions are shown in Fig. (4). Computations of surface pressure indicate that all models are in close agreement with experiment except near the shock wave where the $J-K$ and $q-\omega 2$ models predict shock locations which are slightly upstream of the locations given by experiment and the other models. With regard to skin friction, the $C-S, B-L$ and $q-\omega 2$ models give the best predictions downstream of the shock wave while the $J-K, q-\omega 2$ and $k-\varepsilon$ models are closest in their predictions of displacement thickness. The $k-\varepsilon$ model shows an unrealistically large increase in skin friction downstream of the shock wave. From Table I it is evident that the models giving the best overall predictions of lift and drag are the $J-K, q-\omega 2$ and $k-\varepsilon$ models.

Computed Mach contours and surface distributions for Case 10 are shown in Figs. (5) and (6). In this case the flow downstream of the shock wave is separated for 
some distance. The corresponding model predictions show more differences in surface pressure distributions and especially shock wave locations than in the previous cases and this gives rise to larger differences in lift and drag. It is evident that the $\mathrm{J}-\mathrm{K}$ model provides the best overall predictions of surface pressure, skin friction and displacement thickness distributions as well as lift and drag (Table I). It should be noted in this case that the calculations using the $J-K$ and $q-\omega 2$ models were unsteady with the shock wave undergoing small periodic oscillations about its mean position. The corresponding oscillations in lift were from $2 \%(\mathrm{~J}-\mathrm{K})$ to $48(q-\omega 2)$ of their mean values. The $k-\varepsilon$ model showed an anomalous behavior (or weak instability) in skin friction for this case which is believed to result from numerical stiffness associated with the low-Reynolds-number damping terms of the model (see Ref. 5).

Numerical efficiency of the various turbulence models was measured by the computing time required to achieve steady state, or in the case of unsteady flows, the time required to achieve a periodic state. For the unseparated cases 1 and 9 about 1000 steps were needed for convergence (to approximately 3 significant figures in $C_{L}$ ). Computing time for the zero-equation models was about 480 seconds (on the NASA Ames Cray XMP/48) and about 600 seconds for the two-equation models. For case 10, the models which predicted steady solutions (i.e., C-S, B-L, $k-E, q-\omega 1$ ) required approximately the same time as cases 1 and 9. The unsteady solutions $\left(J-K\right.$ and $q^{-\omega} 2$ models) required about 2.5 times more computing time than the other cases and a constant (instead of spatially varying) time step was used to maintain time accuracy.

The primary conclusions resulting from this work are that differences between experiment and turbulence model predictions which are relatively small for subcritical unseparated transonic flows, become greater for supercritical separated flows. The principal differences between model prediction of lift and $d$ rag for the supercritical cases appear to be the result of differences in predicted shock location. The best overall model in predicting the three cases was the $\mathrm{J}-\mathrm{K}$ model.

\section{References}

${ }^{1}$ Cebeci, T. and Smith, A. M. O., Analysis of Turbulent Boundary Layers, Academic Press, 1974 .

${ }^{2}$ Baldwin, B. S. and Lomax, H., "Thin Layer Approximation and Algebraic Model for Separated Turbulent Flows," AIAA Paper 78-257, 1978.

3 Johnson, D. A., "Predictions of Transonic Separated Flow with an Eddy-Viscosity/Reynolds-Shear-Stress Closure Model," AIAA Paper 85-1683, Cincinatti, OII, Jul. 1985.

${ }^{4}$ Chien, K. Y., "Predictions of Channel Boundary-Layer Flows with a Low-ReynoldsNumber Turbulence Model," AlAA Journal, Vol. 20, Jan. 1982, pp. 33-38.

5 Coakley, T. J., "Turbulence Modeling Methods for the Compressible Navier-Stokes Equations," AIAA Paper 83-1693, Danvers, MA, Jul. 1983. 
${ }^{6}$ Coakley, T. J., and Hsieh, T., "A Comparison Between Implicit and Hybrid Methods for the Calculation of Steady and Unsteady Inlet Flows," AIAA Paper 85-1125, Monterey, CA, Jul. 1985 .

${ }^{7}$ Mehta, U., Chang, K. C., and Cebeci, T., "A Comparison of Interactive Boundary Layer and Thin-Layer Navier-Stokes Procedures," Numerical and Physical Aspects of Aerodynamic Flows III, Ed. T. Cebeci, Springer-Verlag, 1986 .

${ }^{8}$ Coakley, T. J., "Implicit Upwind Methods for the Compressible Navier-Stokes Equations, AIAA Journal, Vol. 23, No. 3, Mar. 1985, p. 374 .

${ }^{9}$ Cook, P. H., McDonald, M. A., and Firmin, M. C. P., AEROFOIL RAE 2822 Pressure Distributions, and Boundary Layer and Wake Measurements," AGARD Advisory Report No. 138,1979 .

Table I - Turbulence Models and Experimental/Computational Characteristics - RAE2 822 Airfoil

\begin{tabular}{|c|c|c|c|c|c|c|c|}
\hline \multirow{2}{*}{ Model } & \multirow{2}{*}{ Originator } & \multicolumn{2}{|c|}{ Case 1} & \multicolumn{2}{|c|}{ Case 9} & \multicolumn{2}{|c|}{ Case 10} \\
\hline & & $\mathrm{C}_{\mathrm{L}}$ & $C_{D}$ & $c_{L}$ & $C_{D}$ & $\mathrm{C}_{\mathrm{L}}$ & $C_{D}$ \\
\hline \multicolumn{8}{|c|}{ Zero-equation models } \\
\hline $\mathrm{C}-\mathrm{S}$ & Cebeci-Smith 1 & .610 & .0086 & .833 & .0172 & .815 & .0269 \\
\hline$B-L$ & Baldwin-Lamax ${ }^{2}$ & .620 & .0087 & .861 & .0185 & .859 & .0298 \\
\hline $\mathrm{J}-\mathrm{K}$ & Johnson-King ${ }^{3}$ & .573 & .0087 & .787 & .0159 & .745 & .0243 \\
\hline \multicolumn{8}{|c|}{ Two-equation models } \\
\hline$k-\varepsilon$ & Chien $^{4}$ & .599 & .0094 & .821 & .0179 & .776 & .0268 \\
\hline$q-\omega 1$ & Coak ley 5 & .607 & .0095 & .846 & .0181 & .836 & .0284 \\
\hline$q-w 2$ & Coak ley ${ }^{6}$ & .576 & .0093 & .783 & .0159 & .726 & .0267 \\
\hline Experime & & .566 & .0085 & .803 & .0168 & .743 & .0242 \\
\hline \multicolumn{8}{|c|}{ 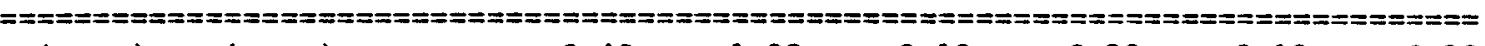 } \\
\hline$\alpha($ geam $)$ & , $\alpha($ comp $):$ & 2.40 & 1.93 & 3.19 & 2.80 & 3.19 & 2.80 \\
\hline$M_{\infty}$ & , $\mathrm{R}_{\mathrm{e}} \times 10^{-6}:$ & .676 & 5.70 & .730 & 6.50 & .750 & 6.20 \\
\hline
\end{tabular}




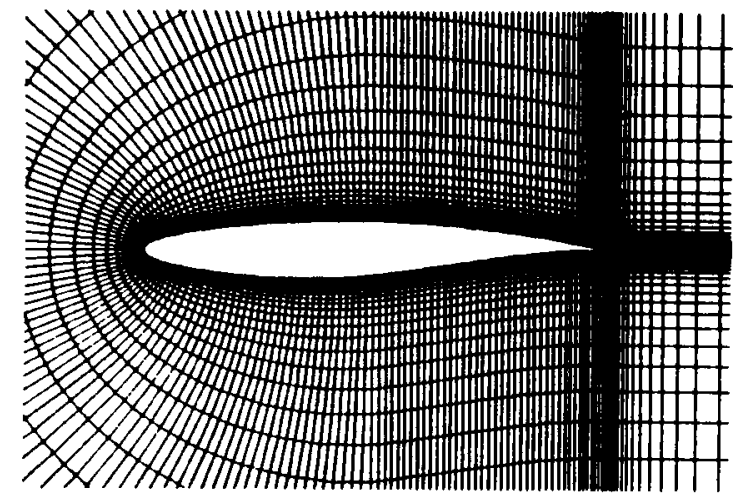

Fig. $1240 \times 60$ C-Mesh, RAE 2822

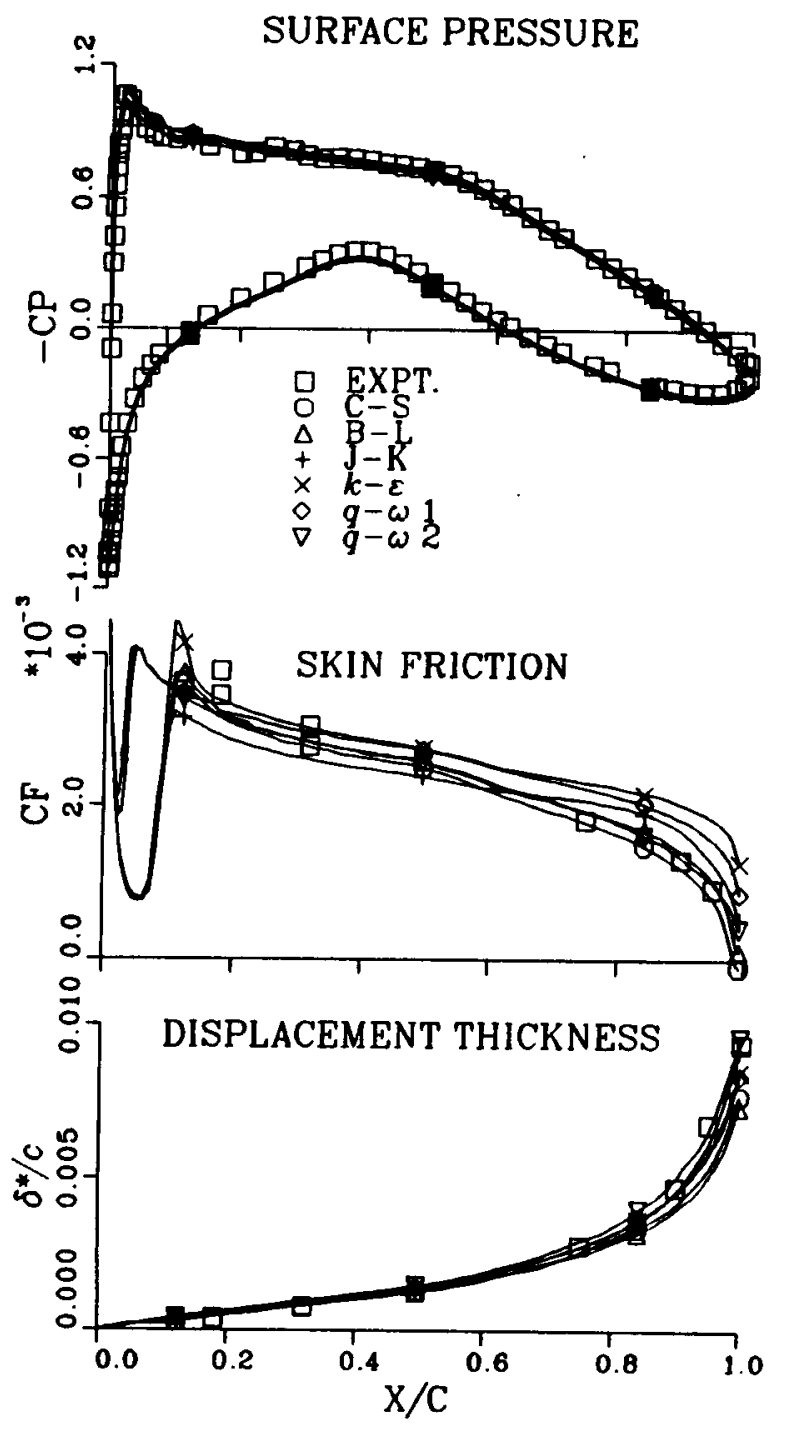

Fig. 2 Surface pressure, upper surface skin friction and displacement thickness distributions, Case 1

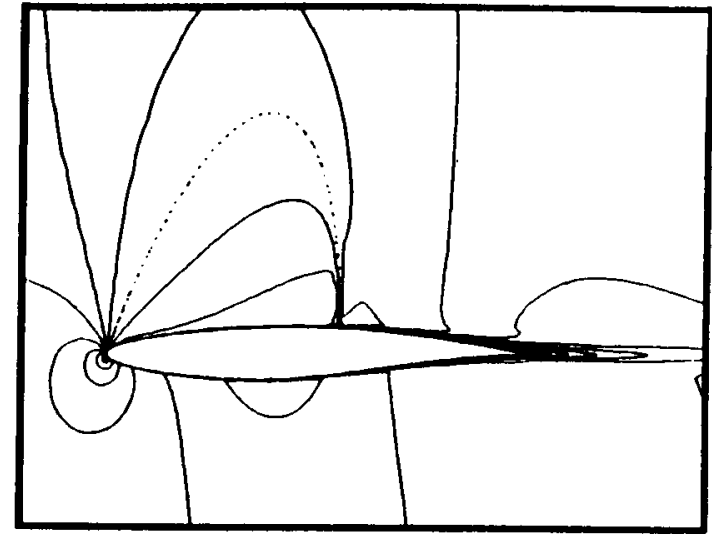

Fig. 3 Mach Contours, Case 9
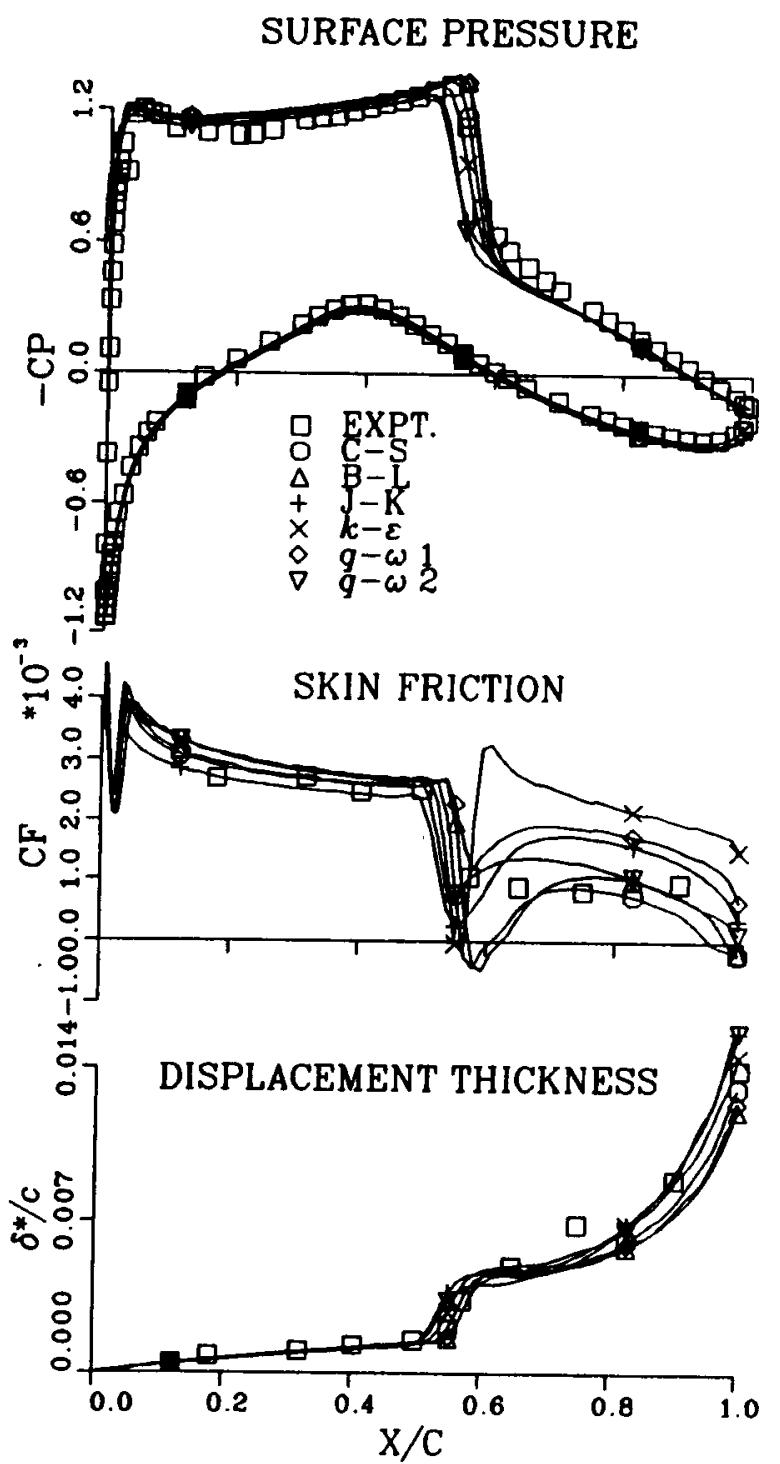

Fig. 4 Surface pressure, upper surface skin friction and displacement thickness distributions, Case 9 


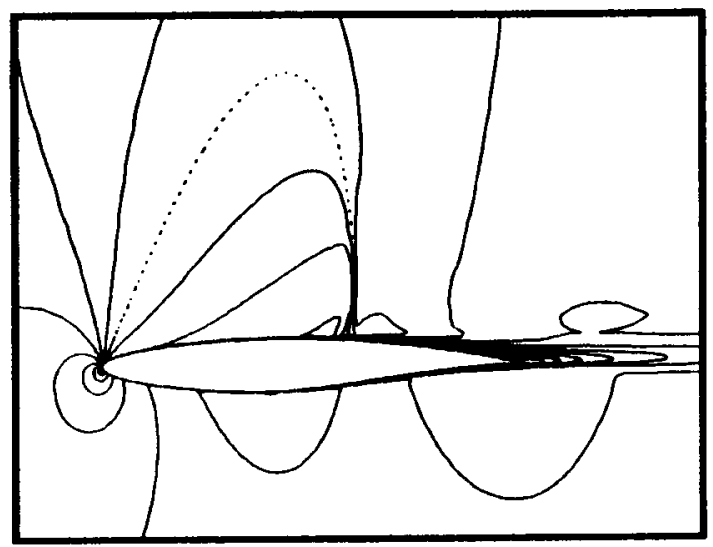

Fig. 5 Mach Contours, Case 10

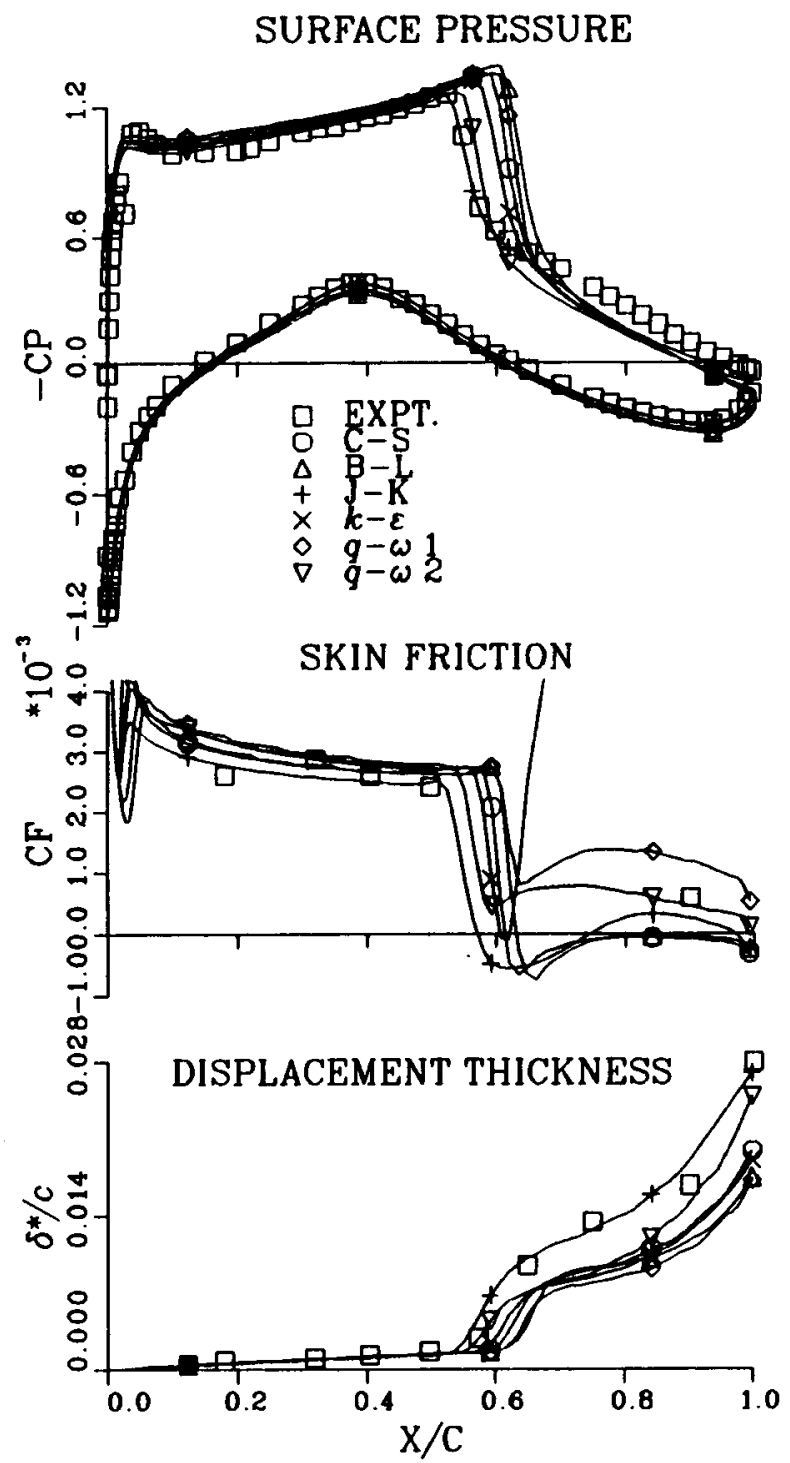

Fig. 6 Surface pressure, upper surface skin friction and displacement thickness distributions, Case 10 


\begin{tabular}{|c|c|c|}
\hline $\begin{array}{l}\text { 1. Report No. } \\
\text { NASA TM-88333 }\end{array}$ & 2. Government Accession No. & 3. Recipient's Cotalog No. \\
\hline \multirow{2}{*}{\multicolumn{2}{|c|}{$\begin{array}{l}\text { 4. Titte and Subtitle } \\
\text { IMPACT OF TURBULENCE MODELING ON NUMERICAL ACCURACY } \\
\text { AND EFFICIENCY OF COMPRESSIBLE FLOW SIMULATIONS }\end{array}$}} & $\begin{array}{l}\text { 5. Report Date } \\
\text { September } 1986\end{array}$ \\
\hline & & 6. Performing Organization code \\
\hline \multirow{2}{*}{\multicolumn{2}{|c|}{$\begin{array}{l}\text { 7. Author(s) } \\
\text { Thomas J. Coakley }\end{array}$}} & $\begin{array}{l}\text { 8. Performing Organization Report No. } \\
\text { A-86326 }\end{array}$ \\
\hline & & \multirow[t]{2}{*}{ 10. Work Unit No. } \\
\hline \multirow{2}{*}{\multicolumn{2}{|c|}{$\begin{array}{l}\text { 9. Performing Organization Name and Address } \\
\text { Ames Research Center } \\
\text { Moffett Field, CA } 94035\end{array}$}} & \\
\hline & & 11. Contract or Grant No. \\
\hline \multirow{3}{*}{\multicolumn{2}{|c|}{$\begin{array}{l}\text { 12. Sponsoring Agency Nome and Address } \\
\text { Nationa1 Aeronautics and Space Administration } \\
\text { Washington, DC } 20546\end{array}$}} & \multirow{2}{*}{$\begin{array}{l}\text { 13. Type of Report and Period Covered } \\
\text { Technical Memorandum }\end{array}$} \\
\hline & & \\
\hline & & $\begin{array}{l}\text { 14. Sponsoring Agency Code } \\
505-60-11\end{array}$ \\
\hline \multicolumn{3}{|l|}{ 15. Supplementary Notes } \\
\hline \multicolumn{3}{|c|}{$\begin{array}{l}\text { Point of Contact: Thomas J. Coakley, Ames Research Center, MS 229-1, } \\
\text { Moffett Field, CA } 94035 \\
\text { (415) } 694-6451 \text { or FTS } 464-6451\end{array}$} \\
\hline \multirow{2}{*}{\multicolumn{3}{|c|}{$\begin{array}{l}\text { Th. Abstract } \\
\text { This paper discusses the numerical implementation of turbulence models } \\
\text { used in viscous compressible flow simulations and describes their perfor- } \\
\text { mance with respect to numerical accuracy, efficiency and stability. The } \\
\text { basic approach utilizes the Reynolds-averaged compressible Navier-Stokes } \\
\text { equations in which the Reynolds stresses and heat fluxes are mathematically } \\
\text { modeled by suitable turbulence models. The turbulence models to be inves- } \\
\text { tigated include zero-, one- and two-equation eddy viscosity models. The } \\
\text { flow fields investigated will include theoretical and supersonic flows about } \\
\text { two-dimensional and axisymetric bodies. Discussions concerning the numeri- } \\
\text { cal implementation of models will include differencing procedures and bound- } \\
\text { ary conditions used to assume numerical stability and accuracy. Numerical } \\
\text { performance will also be evaluated by comparing computations with experi- } \\
\text { mental results. }\end{array}$}} \\
\hline & & \\
\hline $\begin{array}{l}\text { 17. Key Words (Suggested by Author(s)) } \\
\text { Navier-Stokes equations } \\
\text { Turbulence modeling } \\
\text { Compressible flows } \\
\text { Airfoils }\end{array}$ & $\begin{array}{l}\text { 18. Distribution Statemen } \\
\text { Unlimited }\end{array}$ & Subject category - 34 \\
\hline $\begin{array}{l}\text { 19. Security Consif. lof this report) } \\
\text { Unclassiffied }\end{array}$ & $\begin{array}{l}\text { 20. Socurity Classif. (of this pege) } \\
\text { Unclassified }\end{array}$ & \begin{tabular}{c|r} 
21. No. of Pagos & 22. Price" \\
9 & $\mathrm{~A} 022$
\end{tabular} \\
\hline
\end{tabular}

-For sale by the Nationat Technical Information Service, Springfiald, Virginis 22161 